\title{
Sex, gender and women's occupational health: The importance of considering mechanism
}

\author{
Karen Messing ${ }^{\mathrm{a}, *}$, Jeanne Mager Stellman ${ }^{\mathrm{b}}$ \\ ${ }^{a}$ Department of Biological Sciences, Université du Québec à Montréal, Canada \\ ${ }^{\mathrm{b}}$ Mailman School of Public Health, Columbia University, New York, USA
}

Received 12 May 2004; received in revised form 2 December 2004; accepted 24 March 2005

Available online 18 May 2005

\begin{abstract}
A number of researchers have pointed out that less is known about occupational determinants of health in women than in men. The authors examine inventories of ongoing Canadian research and of recent scientific publications in order to identify trends in the approaches used to study women's occupational health (WOH). We also consider conceptual issues in the treatment of the sex and gender of subjects. We observe that women have been the subject of relatively few investigations of occupational health in the natural or biomedical sciences and that studies of WOH have concentrated on the health care professions and on psychosocial stressors, with a deficit in toxicological and physiological studies. We use recent studies of mercury exposure in chloralkali process plants and of musculoskeletal disorders among office workers to provide specific examples of problems in conceptualizing WOH. We propose that WOH be studied more often, especially by researchers in the natural and biomedical sciences, and that such studies include both women and men, where possible, and consider the complex relationships of gender and sex to the pathways involved. More interdisciplinary research would facilitate this process, since social researchers have tended to focus more on gender/sex issues. Our findings demonstrate that it is necessary to explore the implications of using sex routinely as an explanatory variable in occupational health research and to increase emphasis on the mechanisms involved in any sex or gender differences sought or found. From an equity perspective, it is also important to situate biological sex differences so as to prevent them from being used erroneously to justify job segregation or inequitable health promotion measures.
\end{abstract}

(C) 2005 Elsevier Inc. All rights reserved.

Keywords: Sex; Gender-based analysis; Women; Occupational health; Mercury; Methodology

\section{Introduction}

There is some evidence that women's occupational health $(\mathrm{WOH})$ problems are under-compensated and that prevention efforts are less common in women's jobs (Lippel, 1999, 2003; Lippel and Demers, 1996; Lippel et al., 1999; Messing, 1998; Messing and Boutin, 1997). Such inequities can result in suffering, distress, and delays in treatment for women (Reid et al., 1991; Bueckert, 1998; Guberman et al., 2002).

\footnotetext{
${ }^{*}$ Corresponding author. Fax: 15149876183.

E-mail address: messing.karen@uqam.ca (K. Messing).
}

Traditionally, research has played a strong role in leading to action on occupational health, from the time of Alice Hamilton to the present (Stellman and Daum, 1973; Clark, 1987; Thébaud-Mony, 2003; Wegman, 1992). Therefore, research on WOH can probably stimulate and inform prevention efforts. Also, analyses of data on mixed populations in the context of the gender of the participants may be useful in directing occupational health policy and practice. However, good research in women's occupational health (WOH) has been rare (Niedhammer et al., 2000; Zahm et al., 1994, 2000).

In the 1970s and 1980s, research into WOH was simply lacking (Chavkin, 1984; Hunt, 1978; Stellman, 
1978; Stellman and Henifin, 1983; Zahm et al., 1994). More recently, researchers' interest in women has been growing (Messing and de Grosbois, 2001; Zahm and Blair, 2003). This evolution has been encouraged by national initiatives in Canada, the United States, and elsewhere that have called for gender-based analysis and increased inclusion of women in biomedical and epidemiological research generally. (In Canada, the Women's Health Bureau of Health Canada defines gender-based analysis as "a method of evaluation and interpretation which takes into account social and economic differences between women and men, whether applied to policy and program development, or general life activities such as work/family roles" (Women's Health Bureau, 2000). In the United States, the 1993 NIH Revitalization Act was passed with the intention of promoting gender-balanced enrolment in clinical trials and the use of gender-specific analyses of data. Although compliance with such policies has not always been perfect (Ramasubbu et al., 2001; Caron, 2003), researchers have been encouraged to explore sex differences in physiological parameters and in susceptibility to disease (Wizemann and Pardue, 2001) and to environmental toxins (Setlow et al., 1998).

In occupational health, the effects of a policy requirement for gender-based analysis in occupational health and the Swedish National Institute of Working Life's research program on women, work and health are visible in a growing number of Swedish publications on WOH (Bildt and Michelsen, 2002; Nykvist et al., 2002; Torgén and Kilbom, 2000). However, the methods used by many researchers to deal with sex and gender may still be inappropriate or less than adequate (Kennedy and Koehoorn, 2003; Messing, 1998; Messing et al., 2003; Niedhammer et al., 2000).

While there are clear and appropriate public health and scientific advantages from the expanded inclusion of women as subjects and of exposures of concern in women's jobs, it is also necessary to explore the implications of using sex and gender routinely as an explanatory variable in occupational health research without including other variables that either act alone or modify the effects of sex. Social class most readily comes to mind, but there are a multitude of other populationlevel descriptors, which may be as important as sex and gender in influencing the relationships between risk factors and outcomes. From an equity perspective, it becomes important to situate sex and gender differences so as to prevent them from being used erroneously to justify job segregation or inequitable health promotion measures.

In this paper, we will review the recent scientific literature and some ongoing research topics. We ask (1) What kind of research on WOH is being published in the international literature, and how are sex and gender being treated in these studies? (2) What are the gaps in occupational health research regarding women? (3) What research on WOH is ongoing in Canada? (4) What are the possible pitfalls in using sex and gender as explanatory variables when examining occupational health data?

Within the international literature, we chose to examine more closely studies of mercury toxicity in chloralkali plants because we found that this research was concerned with one of the few occupational exposures where specific, quantitative accounting for putative biological sex differences had been applied. Our attention also turned to musculoskeletal problems in offices because this is an area where some gender-sensitive analysis was being performed and the treatment of sex and gender differences within a job was broad enough to include both women and men, with an outcome measure that is common in both sexes. Finally, we chose to examine current Canadian grants because gender-based research is public policy in Canada and we hoped to be able to examine the degree of success with such a policy.

For the purposes of the following discussion, it is useful to recall the definitions of sex and gender used by the Committee on Understanding the Biology of Sex and Gender Differences of the US Institute of Medicine, which defines "sex" as "the classification of living things generally as either male or female, according to their reproductive organs and functions assigned by the chromosomal complement" and "gender" as "a person's self-representation as male or female, or how that person is responded to by social institutions on the basis of the individual's gender presentation" (Wizemann and Pardue, 2001, p. 1). In public health terms, "sex" might be thought to determine genetically-based sensitivity to health determinants and "gender" to express some social forces that could influence exposure and responses to health determinants. However, we are conscious that "sex" and "gender" are hard to disentangle and also multilayered concepts (Fausto-Sterling, 2000).

\section{Methods}

We examined databases that have broad coverage of the international scientific literature as well as those dealing with ongoing research in Canada. We reviewed each article to determine its underlying conceptual framework and the manner in which sex or gender was considered. We only examined peer-reviewed journal articles and excluded studies where type of occupation or employment status were treated as one of many independent socioeconomic variables in association with a health outcome (e.g., role of education, social support, occupation, family status, etc., in relation to depression), unless work content was examined in more detail (e.g., the double workday literature where home and work factors are studied in relation to a health 
outcome). Also excluded were studies that used occupation only as a measure of socioeconomic status in relation to some nonwork-related health outcome. A work-related variable had to be part of the main research question or objective. "Nurse" as an occupational category was also excluded from some analyses for reasons explained below. Abstracts were manually screened and those full papers published in peerreviewed journals that appeared to contain information relevant to health effects of women's work were retained. Two researchers examined the abstracts independently and then the lists of retained articles were pooled. Disagreements about inclusion were resolved either by discussion or, if necessary, by examining the article itself.

An article was retained either if it appeared to contain information on women or if it contained a male-female comparison. It was not retained if it merely reported results on a mixed sample or on men without considering the results according to gender. Three broad categories of studies were retained: those whose study population included women only; those that included both women and men and whose main research question or objective involved a gender-based approach or analysis; those that included an analysis by sex/gender as a subquestion or subobjective but whose main research question or objective did not involve a gender-based approach or analysis. Studies that merely controlled for sex/gender as well as studies that include both women and men in the study population but made no mention of analyses by sex/gender in the abstract were not considered.

\subsection{Database examination}

Four databases that inventory publications in the international scientific literature were searched in February 2003, in order to identify publications pertaining to $\mathrm{WOH}$. These databases represent different disciplines and include: Sociological Abstracts (Sociofile), which includes sociology and related disciplines; PsycINFO (Psychlit) which includes psychology and related disciplines; MEDLINE (PubMed) which includes medicine, nursing, dentistry, veterinary medicine, psychology and preclinical sciences; and Ergonomics Abstracts (http://www.catchword.co.uk/ergonomics/), which includes ergonomics, psychology and related disciplines.

\subsubsection{Searches}

Searches in MEDLINE and PSyINFO were conducted using the general formula women AND (occupation* OR job*) and health, for 2001-2002. However, since this search generated few references in Sociological Abstracts and Ergonomics Abstracts, additional keywords were used to expand the search in these databases only: women AND (occupation* OR job* OR work* OR employ*) and health, for 2001-2002. A supplementary search was carried out in MEDLINE in February 2004 using the job titles of the 10 most common jobs held by women, according to Statistics Canada (Statistics Canada, 2001) using the expression ("sales clerk" OR secretary OR cashier OR teacher OR nurse OR babysitter OR parent helper OR waitress OR food server OR receptionist OR clerk) restricted to titles or abstracts in English referring to populations including human adult females (could also include males) in the years 2001-2003. The initial search yielded 1579 references. "Nurse" yielded a high proportion of nonrelevant references and this keyword was therefore excluded, resulting in retention of 115 references. Titles and, if necessary, abstracts were examined one by one to see if they dealt with occupational health of the occupational groups. Use of the designated group as a control group was excluded. An analogous search was carried out using the job titles of the 10 most common jobs held by men, using the expression ("truck driver" OR janitor OR carpenter OR mechanic OR "retail trade manager" OR farmer OR materials handl* OR "sales representative" OR construction) restricted to titles or abstracts in English referring to populations including human adult males (could also include females) in the years 2001-2003. This yielded 687 references so the search was restricted to 2003, resulting in 210 articles, which were then screened using the same criteria as for the female professions.

\subsection{Ongoing research in Canada}

We sought information from the current websites or most recent annual reports of relevant federal granting agencies on current research on WOH. We included the Canadian Institutes of Health Research (CIHR), the Social Sciences and Humanities Research Council of Canada (SSHRC), and the Centers of Excellence in Women's Health Program of Health Canada (CEWHP). We also included three provincial granting agencies specifically supporting research in occupational health: the Institut de santé et de sécurité du travail du Québec (IRSST), the Institute of Work and Health of Ontario (IWH), and the Workplace Safety Insurance Board of Ontario (WSIB). Publicly available information on projects in progress is confined in the best case to abstracts or brief summaries for news media, and in the worst case, to project titles. We can therefore be sure that we have missed no major current project dealing specifically and principally with $\mathrm{WOH}$ in the organizations surveyed, but not that we have identified all current Canadian projects that are gathering relevant information. Searches were conducted in March 2003, except for the IRSST search, which was done in early 2001. Determination of the discipline of the study was 
derived from the title and abstract, if available, from our knowledge of the researchers involved, and from the information on researchers available from university websites, if we did not know the researchers.

We have no access to grant proposals, only to funded projects. The fact that an agency does not fund a particular type of research may not mean that it has refused proposals in that area. More specifically, methods used were as follows.

\subsubsection{Institut de recherche en santé et en sécurité du travail du Québec (IRSST)}

Since this agency is a major supporter of occupational health research in Canada, with a budget of $\$ 14,710,000$ in 1999, and puts out a detailed annual report, its projects were examined in detail. The IRSST 1999 annual report (the most recent one available at the time of starting the analysis) was examined. It contained abstracts of 129 projects, of which 82 mentioned professions or employment sectors (Institut de recherche en santé et en sécurité du travail (IRSST), 2000). For each of the 88 professions or sectors mentioned in the 82 abstracts, two independent researchers selected the closest one to it in the Statistics Canada list (Population de 15 ans et plus selon la profession, au Québec, 1996). If the profession or sector was not listed, the Bureau de la statistique du Québec kindly offered the necessary figures on women's presence in the occupation in Québec.

The analysis was dependent on the information contained in the published abstract, and no other information was sought or used, even if known informally by the research team. A detailed analysis of these data has been published in French and is summarized below (Messing, 2002).

\subsubsection{Institute of Work and Health of Ontario (IWH)}

We examined the descriptions of the projects in the 2001 (most recent) report of ongoing projects, published at their website, www.iwh.on.ca.

\subsubsection{Workplace Safety Insurance Board of Ontario (WSIB)}

We examined the descriptions of the current projects at their website, www.wsib.on.ca/wsib/wsibsite.nsf/Public/researchprojectsfunded2002\#workrelatedinjuries.

\subsubsection{Canadian Institutes of Health Research (CIHR)}

We searched the descriptions of the CIHR-funded Community Alliances for Health Research (CAHR) and Interdisciplinary Health Research Teams (IHRTs). CIHR also has a database with abstracts of currently funded projects. We searched this for "gender" and "occupation*" and also manually using the subject index and scrutinizing all possible exposure or outcomerelated subjects (e.g., respiration, heart). CIHR is composed of institutes to which funded projects may be associated. We therefore also scrutinized the titles and keywords of projects listed as supported by or identified with the relevant institutes, the 168 projects associated with the Institute for Gender and Health and the 511 projects associated with the Institute for Population and Public Health. A project was retained if it was clearly about gender or sex and occupational health or about women and occupational health or about occupational health associated with a profession known to have a majority of women or about occupation and a health problem associated with or more common among women (e.g., breast cancer, osteoporosis).

\subsubsection{Social Sciences and Humanities Research Council of Canada (SSHRC)}

We searched the Web site for "occupational health," which yielded no useful information. We read the list of standard research grants, major collaborative research initiatives, Initiatives on the New Economy grants, and community-university research alliances, funded in 2002.

\subsubsection{Centers of Excellence in Women's Health Program (CEWHP)}

The centers of excellence, except for the Prairie Women's Health Center of Excellence, have Web sites coordinated by CEWHP where they display their research agendas, listing different projects. We examined the Web sites of the centers of excellence, both the individual Web sites and those linked to the communitybased, CEWHP-supported Canadian Women's Health Network. We also received a list of projects from the Women's Health Bureau (sponsors of CEWHP) detailing the supported projects and we examined the list from 2000 to 2002. For this examination, we had access only to titles of projects for most projects.

\subsection{Mercury toxicity in the chloralkali processes}

The Pub Med database was searched in May 2003 using the terms "mercury" AND "toxic*" AND "chloralkali," with the search limited to Englishlanguage publications concerning adult humans published in 1996-2002. Thirteen references were recovered, two of which did not pertain to possible toxic effects of mercury in chloralkali plants. Eleven full papers were retained, of which five came from the same research group. Other references to literature on mercury toxicity in humans were found in the citations of the original 11 articles. 


\subsection{Musculoskeletal problems among office workers and computer users}

We searched the Pub Med database on November 4, 2004 for papers published in English during the years 2001-2004, dealing with adult human populations, using the search terms (sex OR gender) AND (musculoskeletal OR cumulative trauma OR repetitive strain) AND (office OR computer). We searched the Ergonomics Abstracts database using the same terms (adapted to their search engine) for the same years. We retained 10 peer-reviewed journal articles. Two were from the same research group and shared seven authors, dealing with the same research question and the same study (Balogh et al., 2004; Hansson et al., 2001). Two other papers shared two of four or five authors and discussed very slightly different aspects of the same study (Jensen et al., 2001, 2002). Two other papers shared three of four or five authors and dealt with the same study (Karlqvist et al., 2002; Wahlstrom et al., 2003).

Many mechanisms by which sex and gender could influence prevalence of musculoskeletal problems have been mentioned in the literature (reviews by Kilbom and Messing, 1998; Punnett and Herbert, 2000). These mechanisms were primarily biological susceptibility through hormonal differences, biological susceptibility through muscle composition differences; biological susceptibility/exposure differences through interactions between worksite dimensions and body size; exposure differences through task assignments; effect modification through differences in domestic tasks; reporting differences of various origins and types. We examined the 10 articles to see whether and how these mechanisms were handled.

\section{Results}

\subsection{The international literature}

Overall, we retained one article in six of those initially retrieved from the databases, resulting in a total of 156 occupational health and safety articles published in 2001-2002 (Table 1). Each database yielded a specific distribution of articles, reflecting the discipline covered (Table 1). Unsurprisingly, the Ergonomics Abstracts database was the most likely to deal with musculoskeletal disorders and physical stressors, the Medline database, with physiological phenomena and toxic effects, the Psychlit database, with psychosocial stressors (followed closely by Ergonomics Abstracts), and Sociofile (followed by Psychlit), with work-family issues.

Of these, $72(46 \%)$ were specifically on women; the others were gender-based treatments of data on women and men. Articles retrieved from the natural science databases, Medline and Ergonomics Abstracts, were relatively less likely to be specifically on women. While the remaining papers contained information on gender, many of them consisted solely of male-female comparisons, without consideration of other gender-related factors as explanatory variables. A large number did not consider gender-associated working conditions. The papers specifically on women, or where some analyses of gender differences were done, were much more

Table 1

Summary of literature search results using the search terms, "women and (occupation* or job* or work* or employ*) and health," for 2001-2002, in four databases

\begin{tabular}{|c|c|c|c|c|c|}
\hline & Medline & Ergonomics & Psychlit & Sociofile & Combined \\
\hline Number of papers from initial search & 219 & 221 & 207 & 289 & 936 \\
\hline Number of papers retained & 54 & 22 & 49 & 31 & 156 \\
\hline $\begin{array}{l}\text { Number }(\%) \text { of papers that were on } \\
\text { women specifically }\end{array}$ & $13(24 \%)$ & $5(23 \%)$ & $21(43 \%)$ & $20(65 \%)$ & $59(38 \%)$ \\
\hline $\begin{array}{l}\text { Number }(\%) \text { of papers dealing with } \\
\text { musculoskeletal disorders }\end{array}$ & $13(24 \%)$ & $12(55 \%)$ & $6(12 \%)$ & $3(10 \%)$ & $34(22 \%)$ \\
\hline $\begin{array}{l}\text { Number }(\%) \text { of papers dealing with } \\
\text { cardiovascular or other physiological } \\
\text { phenomena }\end{array}$ & $19(35 \%)$ & $1(5 \%)$ & $9(18 \%)$ & $2(6 \%)$ & $31(20 \%)$ \\
\hline $\begin{array}{l}\text { Number }(\%) \text { of papers dealing with } \\
\text { psychosocial stressors }\end{array}$ & $19(35 \%)$ & $13(59 \%)$ & $30(61 \%)$ & $6(19 \%)$ & $68(44 \%)$ \\
\hline $\begin{array}{l}\text { Number }(\%) \text { of papers dealing with } \\
\text { physical stressors (physical workload, } \\
\text { noise, radiation, etc.) }\end{array}$ & $10(19 \%)$ & $11(50 \%)$ & $7(14 \%)$ & $3(10 \%)$ & $31(20 \%)$ \\
\hline $\begin{array}{l}\text { Number }(\%) \text { of papers dealing with toxic } \\
\text { chemicals }\end{array}$ & $10(19 \%)$ & 0 & $3(6 \%)$ & $1(3 \%)$ & $14(9 \%)$ \\
\hline $\begin{array}{l}\text { Number }(\%) \text { of papers dealing with } \\
\text { work-family balancing and health }\end{array}$ & $2(4 \%)$ & $1(5 \%)$ & $6(12 \%)$ & $5(16 \%)$ & $14(9 \%)$ \\
\hline
\end{tabular}

\footnotetext{
${ }^{\mathrm{a}}$ Since a paper could deal with many different exposures and outcomes, percentages do not add to $100 \%$.
} 
Table 2

Ten most common professions of women in Canada

\begin{tabular}{llll}
\hline Occupation & $\begin{array}{l}\text { Number of } \\
\text { men }\end{array}$ & $\begin{array}{l}\text { Number of } \\
\text { women }\end{array}$ & $\begin{array}{l}\% \\
\text { Women }\end{array}$ \\
\hline Retail sales clerk & 215,345 & 339,025 & 61 \\
Secretary & 5435 & 311,835 & 98 \\
Cashier & 38,805 & 235,585 & 86 \\
Nurse & 12,035 & 220,625 & 95 \\
Accounting clerk & 45,015 & 219,895 & 83 \\
Elementary and & 43,230 & 187,070 & 81 \\
kindergarten teacher & & & \\
Food server & 42,780 & 176,310 & 80 \\
Office clerk & 33,960 & 173,175 & 84 \\
Babysitter, nanny, parent & 6670 & 134,560 & 95 \\
helper & & & \\
Receptionist & 5885 & 118,985 & 95 \\
\hline
\end{tabular}

Note. Calculated from Statistics Canada's Internet Site: http:// www.statcan.ca/english/census96/mar17/occupa/table1/t1p00t.htm, December 7, 2001. Occupations used are three-digit professions.

Table 3

Ten most common occupations of men in Canada

\begin{tabular}{llll}
\hline Occupation & $\begin{array}{l}\text { Number of } \\
\text { men }\end{array}$ & $\begin{array}{l}\text { Number of } \\
\text { women }\end{array}$ & $\begin{array}{l}\% \\
\text { Men }\end{array}$ \\
\hline Truck driver & 222,795 & 4515 & 98 \\
Retail sales clerk & 215,345 & 339,025 & 39 \\
Janitor, concierge & 185,035 & 85,400 & 68 \\
Retail trade manager & 179,645 & 112,900 & 61 \\
Farmer & 176,985 & 52,605 & 77 \\
Wholesale sales & 131,225 & 49,300 & 73 \\
representative (non- & & & \\
technical) & & & 99 \\
Motor vehicle mechanic & 127,185 & 1195 & 90 \\
Materials handler & 119,135 & 13,115 & 99 \\
Carpenter & 112,965 & 1360 & 95 \\
Construction helper & 104,110 & 5775 & \\
\hline
\end{tabular}

Calculated from Statistics Canada's Internet Site: http://www. statcan.ca/english/census96/mar17/occupa/table1/t1p00t.htm, December 7, 2001. Occupations used are three-digit professions. common in the social sciences than in the natural sciences literature.

Tables 2 and 3 present the most common women's and men's jobs in Canada, respectively. The more extensive search done in Medline using the expression ("sales clerk" OR secretary OR cashier OR teacher OR nurse OR babysitter OR parent helper OR waitress OR food server OR receptionist OR clerk) yielded 115 references, from which 10 relevant articles were recovered $(8.7 \%)$. Seven dealt with teachers (occupational stress, voice problems, chalk exposure, infections) and the three others with office clerks, cashiers, and waitresses. The analogous search using the job titles most commonly held by men (truck driver" OR janitor OR carpenter OR mechanic OR "retail trade manager" OR farmer OR materials handl* OR "sales clerk" OR "sales representative" OR construction) yielded 900 references. To keep the number of papers roughly comparable, the search for articles on men's professions was therefore restricted to the year 2003 and thus cut to 210 references, which were screened manually. Fortyfive references $(21.4 \%)$ were relevant, of which 25 dealt with construction workers, 10 with carpenters, seven with farmers, two with truck drivers, and one with mechanics.

\subsection{Ongoing agency-funded research in Canada}

The areas of research of those projects identified as dealing with women or gender and occupational health are presented in Table 4. There were 52 studies in progress, of which more than one-third were in sociology/psychology, and the remainder were divided evenly among ergonomics, epidemiological/biomedical and multidisciplinary or "other" disciplines. The extent of redundancy is not certain since this could not be deduced from project titles (the only information available from some sources) but some redundancy in projects is possible.

Table 4

Number of studies in progress in Canada on women and occupational health, loosely classified by discipline according to available information

\begin{tabular}{|c|c|c|c|c|c|}
\hline $\begin{array}{l}\text { Organizations } \\
\text { funding studies }\end{array}$ & $\begin{array}{l}\text { Sociology/ } \\
\text { psychology }\end{array}$ & $\begin{array}{l}\text { Epidemiology/ } \\
\text { biomedical }\end{array}$ & Ergonomics & $\begin{array}{l}\text { Other/multi- } \\
\text { disciplinary }\end{array}$ & $\begin{array}{l}\text { Total number of } \\
\text { studies }\end{array}$ \\
\hline IRSST & 0 & 0 & 6 & 6 & 12 \\
\hline IWH & 3 & 5 & 3 & 1 & 12 \\
\hline WSIB & 0 & 0 & 0 & 1 & 1 \\
\hline CIHR & 4 & 6.5 & 0.5 & 1 & 12 \\
\hline SSHRC & - & 0.5 & 0.5 & - & 1 \\
\hline CEWHP & 11 & - & 1 & 2 & 14 \\
\hline Total & 18 & 12 & 11 & 11 & 52 \\
\hline
\end{tabular}

${ }^{a}$ IRSST, Institut de santé et de sécurité du travail du Québec; IWH, Institute of Work and Health of Ontario; WSIB, Workplace Safety Insurance Board of Ontario; CIHR, Canadian Institutes of Health Research; SSHRC, Social Sciences and Humanities Research Council of Canada; CEWHP, Centres of Excellence in Women's Health Programme. 
The source of funding is associated with the discipline. The largest volume of research into women, work, and health is supported by the Centers of Excellence in Women's Health Program; this body of work is almost entirely from the social sciences. Although all disciplines are eligible for funds from this source, no ongoing biomedical, physiological, toxicological or epidemiological studies of WOH were found from this source of funding.

Research on women and occupational health, or on gender and occupational health, was also found at two provincial health and safety research agencies, IRSST and IWH and a federal source, CIHR. The IRSST search, which allowed in-depth analysis, will be discussed in detail below. At IWH and CIHR, psychological and sociological research dominated, but a few epidemiological studies were found.

Overall, the subjects studied in Canada are most often the health of nurses, health care workers, and other caregivers. There are two studies on clothing manufacture but none on other factory work and apparently only one on personal services. There is none on office work. Among the top 10 professions of Canadian women (Table 2), only nurses are represented in the ongoing studies.

Psychosocial exposures including stress are studied much more often than toxic exposures or safety problems. There is only one study of chemical exposures and one on accident rates. Musculoskeletal problems are studied principally among health care workers.

In our detailed study of the IRSST research, the professions and sectors concerned by the 129 studies carried out in 1999 had an average of $15 \%$ women workers (compared to a proportion of $46 \%$ women in the labor force). Twelve of the 88 professions/sectors studied were mixed or had a female majority, while the remaining 76 were more than two-thirds male. The former studies received an average grant of $\$ 86,339$ compared to $\$ 114,480$ for those on predominantly male populations. No studies concerned gender or the sexual division of labor.

Previously, we had examined the composition of the six employment groups ranked by the Québec Occupational Health and Safety Commission (CSST) in order of priority for intervention and had noted that, as the priority level increased, the proportion of women decreased (Messing and Boutin, 1997, see also Table 5, last column). We explained this in part by the lack of research on the occupational health of women at the time the priorities were set, in 1979-1981. Fearing a vicious circle, we examined the possibility that women workers were less often subjects of research because their employment groups had lower priority for intervention. As expected, many more grants were given to study workers in groups with high priority. Group I received $\$ 15.53$ per worker in research grants, while group VI received \$0.91 per worker. However, even within each priority group, there were fewer women in the professions and sectors undergoing IRSST-sponsored study than in the corresponding priority group as a whole (Table 5).

\subsection{Mercury in chloralkali process plants}

Although the search resulted in a small number of papers on mercury toxicity in chloralkali plants, they provide examples of ways in which women may be treated in occupational health research papers in the natural sciences. In two papers, subjects were identified as males but the sex of referents was not stated (Barregard et al., 1997; Sallsten and Barregard, 1997). In one paper, women were explicitly excluded (Ellingsen et al., 2000). In three, sex of subjects was not identified at all (Mason et al., 2001; Symanski et al., 2000; Williams et al., 2000). In two cases, sex of the sample was stated but not taken into account and exposure categories were not broken down by sex (Günther et al., 1996; Langworth et al., 1997).

In the remaining two other cases, the authors reported on sex of subjects and attempted to take the sex of the sample into account in examining the data (Frumkin et al., 2001; Urban et al., 1999). In the former, sex was taken into account in calculating toxic effects (Frumkin et al., 2001). The authors, however, could not report the results separately by sex due to small numbers of women $(6.8 \%$ of those exposed, $11.4 \%$ of those not exposed). They therefore combined the data on both sexes using a sex-specific correction factor, on the authority of a paper widely cited in the literature. They stated:

The "predicted" creatinine clearance was based on the formula [(140-age in years $) \times$ weight in $\mathrm{kg}] /$ $\left(P_{\mathrm{Cr}} \times 72\right)$ with a multiplier of 0.85 used for females (Cockcroft and Gault, 1976). We used both the measured weight and the lean body weight in generating the predicted creatinine clearance...

Consultation of the Cockcroft and Gault (1976) reference yields:

Because of different relative amounts of fat and muscle in women, a correction is required. Various authors [2-4] have recommended reducing the predicted $C_{\mathrm{Cr}}$ by $10-20 \%$. A $15 \%$ reduction appears appropriate.

Consultation of Ref. 2 (Jelliffe, 1973) gives us only

For female patients, $90 \%$ of the above value of $C_{\mathrm{Cr}}$ is used.

The authors thus relied on a widely accepted theory that takes account of the fact that women, on average, have a higher percentage of body fat, which affects the 
Table 5

Research supported by IRSST in 1999 where the abstract identifies either a sector or profession associated with a sector, according to the priority for intervention ascribed to the sector (translated from Messing, 2002)

\begin{tabular}{|c|c|c|c|c|}
\hline Priority group & Profession or sector & $\begin{array}{l}\text { Total grant amount per } \\
\text { priority group }\end{array}$ & $\begin{array}{l}\% \text { of women in the } \\
\text { populations studied }\end{array}$ & $\begin{array}{l}\% \text { of women in the } \\
\text { priority group }\end{array}$ \\
\hline $\begin{array}{l}\text { I } \\
(36 \text { mentions of a sector or } \\
\left.\text { profession }^{a}\right)\end{array}$ & $\begin{array}{l}\text { Panel manufacturing, metal } \\
\text { products manufacturing, } \\
\text { mining, metal press } \\
\text { operators, operators of } \\
\text { vibrating portable tools, } \\
\text { electrodepositing and } \\
\text { galvanisation, construction, } \\
\text { public works, forestry, } \\
\text { sawmills, machining }\end{array}$ & $\begin{array}{l}3714063 \$^{b} \\
(4055168 \$)^{\mathrm{c}}\end{array}$ & 2.0 & 14.5 \\
\hline $\begin{array}{l}\text { II } \\
\text { (9 mentions of a sector or } \\
\text { profession) }\end{array}$ & $\begin{array}{l}\text { Transportation equipment } \\
\text { production, plastics } \\
\text { production, automobile } \\
\text { manufacturing, automobile } \\
\text { painting, industrial pottery, } \\
\text { metallurgy }\end{array}$ & $\begin{array}{l}955870 \$^{b} \\
\left(\begin{array}{lll}1 & 143937 \$\end{array}\right)^{\mathrm{c}}\end{array}$ & 14.5 & 15.7 \\
\hline $\begin{array}{l}\text { III } \\
\text { ( } 9 \text { mentions of a sector or } \\
\text { profession) }\end{array}$ & $\begin{array}{l}\text { Vehicle driving, materials } \\
\text { handling, poultry } \\
\text { processing, pulp and paper } \\
\text { workers, transport and } \\
\text { storage }\end{array}$ & $\begin{array}{l}2227461 \$^{\mathrm{b}} \\
(2271017 \$)^{\mathrm{c}}\end{array}$ & 8.6 & 28.0 \\
\hline $\begin{array}{l}\text { IV } \\
\text { ( } 8 \text { mentions of a sector or } \\
\text { profession) }\end{array}$ & $\begin{array}{l}\text { Cooks, sewage } \\
\text { maintenance, convenience } \\
\text { store employees, } \\
\text { supermarket employees } \\
\text { except cashiers, machine } \\
\text { production, food service } \\
\text { industry employees, } \\
\text { automobile service workers }\end{array}$ & $\begin{array}{l}611208 \$^{b} \\
(843075 \$)^{c}\end{array}$ & 45.5 & 42.0 \\
\hline $\begin{array}{l}\mathrm{V} \\
\text { (11 mentions of a sector or } \\
\text { profession) }\end{array}$ & $\begin{array}{l}\text { Ambulance personnel, } \\
\text { hairdressers, street cleaners, } \\
\text { firefighters, electric and } \\
\text { electronics workers, cinema } \\
\text { and video technicians, } \\
\text { printing, electric products }\end{array}$ & $\begin{array}{l}962640 \$^{\mathrm{b}} \\
\left(\begin{array}{lll}1 & 265 & 175 \$)^{\mathrm{c}}\end{array}\right.\end{array}$ & 26.0 & 48.7 \\
\hline $\begin{array}{l}\text { VI } \\
\text { ( } 9 \text { mentions of a sector or } \\
\text { profession) }\end{array}$ & $\begin{array}{l}\text { Gardeners, medical } \\
\text { personnel, truck gardening, } \\
\text { clothing, laboratory } \\
\text { personnel }\end{array}$ & $\begin{array}{l}693925 \$^{b} \\
(769662 \$)^{c}\end{array}$ & 49.8 & 64.5 \\
\hline
\end{tabular}

Source: IRSST (2000). The proportion of women by priority group was kindly provided by IRSST from 1996 census data obtained from Statistics Canada. The list of groups was obtained from the statistical appendix of the 1999 annual report prepared by the Service de la statistique et de la gestion de l'information under the direction of Jean-Guy Lemieux, Québec, CSST, pp.145-146.

${ }^{a}$ Several sectors and professions occurred more than once.

${ }^{\mathrm{b}}$ When more than one profession was mentioned in an abstract, the amount of the grant was arbitrarily divided by the number of professions and that amount is used to calculate the first total.

${ }^{\mathrm{c}}$ When more than one profession was mentioned in an abstract, the full amount of the grant was ascribed to each profession and that amount is used to calculate the total in parentheses.

relationship between measured body weight and mercury metabolism. However, such reliance on a generalization from population differences to individual workers could potentially lead to misinterpretation of the data. Given that the unexposed group had $68 \%$ more women than the exposed group, the use of an erroneous correction might have led to error, either overestimating or underestimating effects on renal function. In addition, we need to know whether women and men were exposed differentially. The companion paper (Williams et al., 2000) that explained the calculation of exposure data by occupational group did not give any information on gender. If, as is probable, the women were found preferentially in 
low-exposure office jobs, the use of correction factors may have distorted the exposure-effect relationship.

\subsection{Musculoskeletal problems and sex and gender in office work}

All 10 papers reviewed reported the sex composition of their samples, and all reported outcome by sex. One of these (Ortiz-Hernandez et al., 2003) found no sex difference in outcome. Of the seven separate studies examined in the 10 papers, two gave no information on exposure by sex (Gerr et al., 2002; Ortiz-Hernandez et al., 2003). For two of the five remaining studies, information was incomplete and not sufficient to contribute to an understanding of the relation between exposure and effect for women and men (Balogh et al., 2004; Devereux et al., 2002). Because women usually report more symptoms and are assigned to different tasks, stratification by sex is the recommended procedure for analyzing mixed-sex data (Messing et al., 2003; Punnett and Herbert, 2000). Three studies stratified analyses by sex (Karlqvist et al., 2002; Jensen et al., 2001; Seppäla, 2001), while the others either did not incorporate sex or gender in the data analysis or treated sex as a confounder.

Explanations for a sex difference in outcome were discussed in four of the six studies that found such a difference. One of these (Devereux et al., 2002) considered a single hypothesis, that of gender differences in exposure, and rejected that explanation. However, risk factors for symptoms in the neck and upper limb considered in this paper included only exposure to heavy lifting or to vibrations, but not to repetitive movements; all women were classed in the low-exposure group. The three other studies that discussed women's higher symptom prevalence all considered exposure differences carefully, and all found them to be partly responsible for the difference in outcome. The residual sex/gender difference was discussed in two studies, one of which proposed hypothetical differences in work technique (Jensen et al., 2001, 2002) and the other considered, evaluated and dismissed an explanation involving home exposure to computers and also suggested that work station design may not have been appropriate for the average-sized woman (Karlqvist et al., 2002). Although three studies mentioned a possible biological or "constitutional" susceptibility, none specified or discussed potential biological bases for such a susceptibility.

\section{Discussion}

\subsection{Limits of the present study}

We cannot be sure that our coverage of the databases or the Canadian ongoing research is complete or evenly distributed by discipline. The keywords used were rather general, and may have been more successful in identifying broader, multidisciplinary studies than more focused or specific studies. To the extent that this is the case, we have probably undersampled research in $\mathrm{WOH}$ from natural science sources. Also, gender may appear to be a more relevant or salient characteristic to researchers in the social sciences, so WOH research in these disciplines may have been more easily identified.

We hoped to remedy some of the failings of these methods by more in-depth searches. Specifically, since the Medline database has the widest coverage in terms of disciplines, searching it by the names of occupation should have uncovered journal articles missed by other methods. Also, examination of the IRSST annual report, which contained a summary of the ongoing projects, should have allowed us to see the treatment of WOH by an occupational health and safety granting organization.

\subsection{Disciplines where research is done on women or gender and occupational health}

Research on WOH appears to vary by discipline. From Table 1, it appears that the majority of research involving women or gender concerns psychosocial stressors; such work is found primarily by searching Psychlit and Sociofile but is also in the other two databases. From Table 4, it appears that WOH research profits from the specific attention of an organization sponsoring research on women's health, but that, again, such attention appears to be concentrated in the social sciences. In contrast to the research on construction workers, farmers and even carpenters, relatively little attention appears to be given to toxic, physiological or physical exposures in women's jobs.

We conclude that women have been the subject of relatively few investigations of occupational health in the natural or biomedical sciences. Studies of WOH have concentrated on the health care professions, and on psychosocial stressors. Toxicological and physiological studies have been lacking.

\subsection{Research on women and occupational health}

Data from the Quebec IRSST showed that women were under-represented in the professions and sectors studied in 1999. These had, on average, $15 \%$ women, compared to a percentage of women of $45 \%$ in the Quebec labor force around the time the studies were initiated (Bureau de la statistique du Québec, 1997). This large discrepancy, mirrored to some extent in the results of the Medline search by job title, could possibly be explained if women work in areas where there is little risk for their health. However, among women's top professions, there are serious health risks (McDiarmid 
and Gucer, 2001; Messing, 1998; Stellman, 1978). For example, many food servers lift heavy objects, follow exacting work schedules, and face prolonged standing, and other risks. Sales clerks and (in North America) cashiers and tellers also suffer from prolonged standing. Office workers are exposed to various ergonomic constraints. These occupations are not, however, found in the sectors given high priority for intervention and research in Québec (Messing and Boutin, 1997). However, as seen in Table 5, even within the high-priority areas, women's professions and sectors receive less attention.

We therefore consider some additional explanatory hypotheses. First, it is likely that the research themes given priority by the Institute's board of directors (accidents, personal protective equipment, noise and vibrations, tool and machine safety, chemicals, musculoskeletal disorders) are more relevant for professions occupied by men (Messing, 2002). This type of study is usually done by researchers in engineering or the natural sciences.

Second, in order to appreciate the importance of considering occupational health by gender, some training or interest in the social sciences is probably necessary, combined with a thorough knowledge of occupational health and safety issues. Such interdisciplinary studies are rather rare.

More broadly, we can observe that no researchers, including ourselves, have thoroughly explored the need for occupational health research on women, either by (1) systematically examining the risks in women's common professions (Table 2); (2) systematically surveying or sampling women workers' exposures to reveal the most important risks; or (3) systemically examining the most common health problems of women (e.g., osteoporosis, menstrual cycle dysfunction, chronic fatigue syndrome, fibromyalgia, menopausal symptoms, multiple chemical sensitivity, migraines, sleep disturbances, and varicose veins) to determine possible occupational components, although some work has been initiated with regard to occupational cancers (Blair et al., 1999; Zahm and Blair, 2003). Such research should be encouraged.

\subsection{Adequacy of gender-based research models}

Although our data show a need for more research on sex, gender and occupational health, simply taking gender into "account" may be inappropriate in occupational health studies (Bond et al., 2004; Mergler, 1995; Messing et al., 2003; Niedhammer et al., 2000; Punnett and Herbert, 2000). For example, many studies that include women state that they "control" for gender rather than considering gender, sex, and associated covariates and confounders in the conceptual framework of the study. Male-female comparisons of outcomes are often made with no reference to the many exposure parameters that are associated with gender, leaving the impression that female sex alone makes women more (or less) vulnerable to various occupational health outcomes such as accidents, sick building syndrome, carpal tunnel syndrome, and stress. This was found to be the case in some studies of musculoskeletal symptoms in office workers. In addition, the majority of studies examined did not consider explanations other than exposure differences, such as design of the workstation in relation to anthropometric measurements, domestic workload, and reporting differences. The fact that no study in this group considered at all carefully the potential biological mechanisms underlying the difference in outcome is striking, considering that three papers invoked such a mechanism, which is also an implied default explanation for the other papers. However, analysis of this group of papers did show that a substantial minority (three of seven) thoroughly explored male-female exposure differences and treated them carefully. All three of these studies came from the Scandinavian countries, which may be developing a tradition of gender-sensitive research in ergonomics (Kilbom et al., 1998).

The case of mercury toxicity in chloralkali process plants, though it concerns only a small group of papers, provides examples of the varying contemporary research approaches to the challenge of treating mixed-sex samples in the biomedical sciences: failure to identify the sex of the sample; exclusion of women; failure to consider sex at all in a mixed sample. The one study that sought to take sex into account in a thoughtful way used a correction factor that, while published in a peerreviewed journal and cited in other studies, appears to be arbitrary. We must ask: What are the effects of using an inappropriate correction factor in this case? Is it necessary or desirable to use a correction factor in this type of situation? If so, what kind of correction factor should be used? Since such data on the validity of most "correction factors" are unavailable, we suggest that correction factors be used with extreme caution.

\subsection{Mechanism-based sex-gender-occupational health research needed}

In our view, the above problems would best be avoided by formulating research hypotheses more precisely, taking into account complex pathways and paying careful attention to underlying biological and social mechanisms. We must first confront the implicit presumption that there is less within-sex diversity in size, shape, and composition than divergence between the sexes. In the mercury example, the mechanism implied is a body surface/volume ratio-based biological mechanism, implying a necessary correction for proportion of body fat. If this is thought to be necessary, should not proportion of body fat be measured directly by one of 
the easily available noninvasive methods such as the use of calipers? Using sex as a surrogate for the proportion of body fat would seem unnecessary. In considering what kinds of correction factors should be used in the chloralkali process case, the absence of a usable correction factor for creatinine or for BSA is presumably what a more careful study of sex differences is meant to remedy, by providing science-based correction factors and guidance about when to use them.

Hypotheses need to be precisely worded and identify characteristics that stem directly from biological sex, such as hormonal titers, as distinguished from characteristics more loosely associated with sex, such as height or physical strength. When a possible pathway between sex and a health effect is proposed, it is necessary to elucidate and measure indicators of the intervening steps. For example, in studies of upper limb musculoskeletal problems related to repetitive work, it would be relevant to measure upper limb dimensions or at least request height as a surrogate measure in studies of large populations. If sex is hypothesized to determine trunk height, making the angle between the trunk and the vertical less favorable for women at office worksites, it would be best to measure the trunk angle instead of just using sex as a proxy for trunk height. If this cannot be done in practice, at least the underlying hypotheses and assumptions should be made explicit.

Hypotheses that encompass social roles or psychological attributes can have varying degrees of association with gender, or they may involve sex-typed task assignments associated with certain exposures. These distinctions as to mechanism are important because research can influence prevention practices. Strategies for prevention of common health problems such as carpal tunnel syndrome among women workers will differ according to whether the observed male-female differences are attributed to effects of pregnancy or other hormone-related phenomena (Leclerc et al., 1998), to interactions between jobsite dimensions and anthropometric characteristics (Stetson et al., 1992), or to sextyped task assignments resulting in differences in exposure (McDiarmid et al., 2000; Punnett and Herbert, 2000). It has been pointed out by several authors (Doyal, 2001; Krieger, 2003; Messing et al., 2003) that failure to consider the mechanisms determining men's higher rate of certain health problems, such as occupational accidents, may interfere with prevention.

We recognize that testing more precise hypotheses presents methodological challenges. Commonly used multivariate analyses may not be sufficient to answer many of these kinds of questions and more sophisticated modeling which takes into account the complexity of the many pathways in the model may be necessary, implying expenses for more extensive data collection. Similarly, more sensitive procedures and laboratory analyses will probably have to be developed. Sometimes the popula- tion at risk may not be sufficiently large or exposures sufficiently varied to permit adequate analysis of complex models. In such cases, however, it is important to discuss the lacunae in the study rather than letting the reader assume that either sex or gender is the true explanatory variable.

In our view, doing studies on sex, gender and occupational health without regard to mechanism poses important risks for both the acquisition of knowledge and the equitable design of policy. Large-scale studies, where "sex" may be the only descriptor available, may need to be complemented by qualitative studies where mechanisms can be more fully explored.

\subsection{Possible risks of inaccuracy}

In our view, five types of risks can be anticipated from the routine and insufficiently critical examination of sex and gender differences in health research:

1. There is a risk of false positives or false negatives, i.e., of discovering sex differences where none in fact exist, or of missing true effects. These risks arise in any large set of studies, from the fact that, randomly, one in 20 studies of sex differences will result in statistical significance at the 0.05 level, and that, on the other hand, study power may be insufficient to reveal differences. In addition, since not all studies carefully check all relevant characteristics of their samples, age, fitness, or nutritional differences or even differences in sample size may be interpreted as sex differences. The public interest in sex differences may then result in hasty conclusions that have detrimental effects on public health policy and on the body of scientific knowledge.

There is a corresponding risk of false negatives when male and female populations are not of equal size, are not well matched, or when outcomes or risk factors primarily relevant for only one sex are not considered. In this case there is a danger that health problems for one group may be missed or risk factors overlooked.

2. There is a risk of overemphasizing sex differences in relation to other anatomical and physiological contributions to population variation. The most obvious cases are those involving sex differences in body size. No one would dispute that, on the average, men are taller, larger, and heavier than women, contributing to sex differences in a number of other important health-related variables such as blood volume and oxygen consumption. But the relevant source of variation may be the size difference, not the sex difference, and may not apply to small men or large women. It is undeniably easier to record sex than to measure the relevant body dimensions, but it may not be as good a predictor (Bylund and Burstrom, 2003). 
3. Sex differences can be overemphasized if mean differences are reported but the population distributions are not. Sampling from populations at Canadian army bases indicates that women's average wrist to index finger length is $170 \mathrm{~cm}$ and men's is $183 \mathrm{~cm}$ (7.6\% higher). The hands of about $92 \%$ of the women are shorter than that of the average man, and the hands of about $92 \%$ of the men are longer than that of the average woman. However, $36 \%$ of the women's and $46 \%$ of the men's are between 170 and $183 \mathrm{~cm}$ long (Chamberland et al., 1998). Both the difference and the degree of overlap are important, e.g., when examining the induction of repetitive strain injuries attributable to hand-tool interactions (McDiarmid et al., 2000; Messing and Stevenson, 1996). When anthropometric considerations are factored into consideration of the effects of exposures, the apparent gender differences may disappear (Bylund and Burstrom, 2003; Stetson et al., 1992).

For many parameters, it is unwise to presume that the average sex difference applies to all or even most individuals in a population. Women are said to have an average of $25 \%$ fat by body weight, compared to $15 \%$ for men (Parker, 2000), or $0.26 \mathrm{~kg}$ fat-free mass per $\mathrm{cm}$ height compared to 0.36 for men (Clarkson and Going, 1996). This difference has been invoked in discussions of absorption of various fat-soluble toxins. However, percent fat varies among women and men according to age, physical fitness and training (Clarkson and Going, 1996), and researchers rarely have information on whether the population studied is typical in this regard. Attributing (by implication) $25 \%$ body fat to a slender fashion model and $15 \%$ to male sumo wrestlers is likely to diminish the accuracy of a study.

In addition, both women and men are subject to circadian and other time-based variations in physiological state, and physiological states vary with life cycle in both sexes. For some parameters such as blood chemical concentrations, variations within a sex over time can exceed average sex differences (Yokoyama et al., 2000).

4. There is a very large risk of confusion between sex and gender differences. In practice, sex and gender are not easy to unravel, given the multiple interactions between genes and environment in producing human health. Body fat/muscle ratios, e.g., are determined not only (or even primarily) by sex hormones, but by nutritional practices that are influenced by socialization of males and females in relation to the constantly changing and culturedependent social demands for preferred body types for their respective sex. Nutritional and exercise practices, in turn, influence the secretion of sex hormones, with effects that vary with sex and within a sex (e.g., amenorrhea among anorexics and athletes). In this complex situation, it is especially important to concentrate on the putative mechanism by which a reported male-female health difference (e.g., prevalence of depression or osteoporosis) is to be attributed to sex or to gender-related exposure.

5. There is a risk of overemphasizing gender differences in relation to other effect modifiers in occupational health studies. Ethnicity, culture, social class, family type, and age are among the many other explanatory variables that may be involved in processes that produce health or illness (Alexanderson, 1998; Krieger et al., 1997; Meinert and Gilpin, 2001).

\section{Conclusions}

More research on women, sex/gender and occupational health is necessary and desirable, particularly in natural and biomedical science-based research. However, researchers may produce results that can be badly interpreted. In our view, researchers wishing to deal with sex/gender and occupational health need to pay even more attention than is usual to the possible social and physiological mechanisms underlying the phenomena under study and to appreciate the complexity of the applicable social and biological models, in order to formulate appropriate and interesting hypotheses. In this way, they can avoid contributing to scientific confusion and eventual policy errors. Failing to make hypotheses on sex and gender explicit and complete may, in fact, produce results purporting to show that sex and gender lead in themselves to differentiated health risks that may be interpreted to the prejudice of one sex or the other. Finally, it should also be recognized that the gender/sex interaction may be so inextricably linked in practice that complete separation may not be possible in any real-life study. Researchers thus may want to be circumspect about the scope of their findings.

\section{Acknowledgments}

This study was supported by grants to KM from the Centers of Excellence in Women's Health Program of Health Canada and the Social Sciences and Humanities Research Council of Canada. KM is recipient of a Senior Investigator Award from the Canadian Institutes of Health Research. The authors thank Stephanie Premji for able technical and substantive assistance.

\section{References}

Alexanderson, K., 1998. Measuring health. Indicators for working women. In: Kilbom, Å., Messing, K., Thorbjornsson, C. (Eds.), Women's Health at Work. National Institute for Working Life, Stockholm, pp. 121-161. 
Balogh, I., Orbaek, P., Ohlsson, K., Nordander, C., Unge, J., Winkel, J., Hansson, G.A., 2004. Self-assessed and directly measured occupational physical activities-influence of musculoskeletal complaints, age and gender. Appl. Ergon. 35 (1), 49-56.

Barregard, L., Enestrom, S., Ljunghusen, O., Wieslander, J., Hultman, P., 1997. A study of autoantibodies and circulating immune complexes in mercury-exposed chloralkali workers. Int. Arch. Occup. Environ. Health 70 (2), 101-106.

Bildt, C., Michelsen, H., 2002. Gender differences in the effects from working conditions on mental health: a 4-year follow-up. Int. Arch. Occup. Environ. Health 75 (4), 252-258.

Blair, A., Zahm, S.H., Silverman, D.T., 1999. Occupational cancer among women: research status and methodologic considerations. Am. J. Ind. Med. 36 (1), 6-17.

Bond, M.A., Punnett, L., Pyle, J.L., Cazeca, D., Cooperman, M., 2004. Gendered work conditions, health, and work outcomes. J. Occup. Health Psychol. 9 (1), 28-45.

Bueckert, L., 1998. The role of social support in women's occupational health. In: Tissot, F., Messing, K. (Eds.), Improving the Health of Women in the Work Force: A Meeting of Representatives of Women Workers and Researchers. Proceedings of a Colloquium Held at the Université du Québec à Montréal, March 26-28, 1998. Health Canada, Ottawa, pp. 27-31.

Bureau de la statistique du Québec, 1997. Les conditions de vie au Québec en faits saillants. Institut de la statistique du Québec, Québec.

Bylund, S.H., Burstrom, L., 2003. Power absorption in women and men exposed to hand-arm vibration. Int. Arch. Occup. Environ. Health 76 (4), 313-317.

Caron, J., 2003. Report on Governmental Health Research Policies Promoting Gender or Sex Differences Sensitivity. Institute of Gender and Health, Canadian Institutes of Health Research, Ottawa, Canada, http://www.cihr-irsc.gc.ca/e/pdf_25502.htm.

Chamberland, A., Carrier, R., Forest, F., Hachez, G., 1998. Anthropometric Survey of the Land Forces. Defence and Civil Institute of Environmental Medicine, North York, Ontario, Canada.

Chavkin, W. (Ed.), 1984. Double Exposure: Women's Health Hazards on the Job and at Home. Monthly Review Press, New York.

Clark, C., 1987. Physicians, reformers and occupational disease: the discovery of radium poisoning. Women Health 12 (2), 147-167.

Clarkson, P., Going, S., 1996. Body composition and weight control: a perspective on females. Perspect. Exercise Sci. Sports 9, 147-214.

Cockcroft, D.W., Gault, M.H., 1976. Prediction of creatinine clearance from serum creatinine. Nephron 16 (1), 31-41.

Devereux, J.J., Vlachonikolis, I.G., Buckle, P.W., 2002. Epidemiological study to investigate potential interaction between physical and psychosocial factors at work that may increase the risk of symptoms of musculoskeletal disorder of the neck and upper limb. Occup. Environ. Med. 59 (4), 269-277.

Doyal, L., 2001. Sex, gender, and health: the need for a new approach. Br. Med. J. 323, 1061-1063.

Ellingsen, D., Efskind, J., Berg, K.J., Gaarder, P.I., Thomassen, Y., 2000. Renal and immunologic markers for chloralkali workers with low exposure to mercury vapor. Scand. J. Work Environ. Health 26 (5), 427-435.

Fausto-Sterling, A., 2000. Sexing The Body: Gender Politics and the Construction of Sexuality. Basic Books, New York.

Frumkin, H., Letz, R., Williams, P.L., Gerr, F., Pierce, M., Sanders, A., Elon, L., Manning, C.C., Woods, J.S., Hertzberg, V.S., Mueller, P., Taylor, B.B., 2001. Health effects of long-term mercury exposure among chloralkali plant workers. Am. J. Ind. Med. 39 (1), 1-18.

Gerr, F., Marcus, M., Ensor, C., Kleinbaum, D., Cohen, S., Edwards, A., Gentry, E., Ortiz, D.J., Monteilh, C., 2002. A prospective study of computer users. I. Study design and incidence of musculoskeletal symptoms and disorders. Am. J. Ind. Med. 41 (4), 221-235.
Guberman, N., Lippel, K., Lefebvre, M-C., Côté, D., Schmidt, C., 2002. L'expérience des travailleurs et des travailleuses dans l'exercice de leurs droits: l'audience à la C.L.P., october 2002. University of Québec at Montréal, Montréal.

Günther, W., Sietman, B., Seeber, A., 1996. Repeated neurobehavioral investigations in workers exposed to mercury in a chloralkali plant. Neurotoxicology 17 (3-4), 605-614.

Hansson, G.A., Balogh, I., Bystrom, J.U., Ohlsson, K., Nordander, C., Asterland, P., Sjolander, S., Rylander, L., Winkel, J., Skerfving, S., 2001. Questionnaire versus direct technical measurements in assessing postures and movements of the head, upper back, arms and hands. Scand. J. Work Environ, Health 27 (1), 30-40.

Hunt, V., 1978. Work and the Health of Women. CRC Press, Boca Raton, FL.

IRSST (Institut de recherche en santé et en sécurité du travail), 2000. Rapport Annuel 1999. IRSST, Montréal.

Jelliffe, R.W., 1973. Letter: creatinine clearance: bedside estimate. Ann. Intern. Med. 79 (4), 604-605.

Jensen, C., Finsen, I., Sogaard, K., Christensen, H., 2001. Musculoskeletal symptoms and duration of computer and mouse use. Int. J. Ind. Ergon. 30 (4-5), 265-275.

Jensen, C., Ryholt, C.U., Burr, H., Villadsen, E., Christensen, H., 2002. Work-related psychosocial, physical and individual factors associated with musculoskeletal symptoms in computer users. Work and Stress 16 (2), 107-120.

Karlqvist, L., Tornqvist, E.W., Hagberg, M., Hagman, M., Toomingas, A., 2002. Self-reported working conditions of VDU operators and associations with musculoskeletal symptoms: a cross-sectional study focusing on gender differences. Int. J. Ind. Ergon. 30 (4-5), 277-294.

Kennedy, S.M., Koehoorn, M., 2003. Exposure assessment in epidemiology: does gender matter? Am. J. Ind. Med. 44 (6), 576-583.

Kilbom, Å., Messing, K., 1998. Work-related musculoskeletal disorders. In: Kilbom, Å., Messing, K., Thorbjornsson, C. (Eds.), Women's Health at Work. National Institute for Working Life, Sweden, pp. 203-231.

Kilbom, A., Messing, K., Thorbjornsson, C. (Eds.), 1998. Women's Health at Work. National Institute for Working Life, Stockholm.

Krieger, N., 2003. Genders, sexes, and health: what are the connections - and why does it matter? Int. J. Epidemiol. 32, 652-657.

Krieger, N., van den Eeden, S.K., Zava, D., Okamoto, A., 1997. Race/ ethnicity, social class, and prevalence of breast cancer prognostic biomarkers: a study of white, black, and Asian women in the San Francisco bay area. Ethnic Dis. 7 (2), 137-149.

Langworth, S., Sallsten, G., Barregard, L., Cynkier, I., Lind, M.L., Soderman, E., 1997. Exposure to mercury vapor and impact on health in the dental profession in Sweden. J. Dent. Res. 76 (7), 1397-1404

Leclerc, A., Touranchet, A., Rondeau du Noyer, C., Gournay, M., Vallayer, C., Maillard, M.C., Delemotte, B., Roquelaure, Y., Mereau, P., Franchi, P., 1998. Le rôle des facteurs hormonaux dans le syndrome du canal carpien chez la femme. Arch. Maladies Prof. $59,30-31$.

Lippel, K., 2003. Compensation for musculo-skeletal disorders in Quebec: systemic discrimination against women workers? Int. J. Health Serv. 33 (2), 253-282.

Lippel, K., 1999. Workers' compensation and stress: gender and access to compensation. Int. J. Law Psychiatry 22 (1), 79-89.

Lippel, K., Demers, D.L., 1996. L'invisibilité : facteur d'exclusionLes femmes victimes de lésions professionnelles. Rev. Can. Droit Soc. 11 (2), 87-133.

Lippel, K., Messing, K., Stock, S., Vézina, N., 1999. La preuve de la causalité et l'indemnisation des lésions attribuables au travail répétitif: rencontre des sciences de la santé et du droit. [Proof of 
causality and compensation of disorders associated with repetitive work: a meeting of science and law]. Windsor Yearbook of Access to Justice $17,35-86$.

Mason, H., Hindell, P., Williams, N.R., 2001. Biological monitoring and exposure to mercury. Occup. Med. (London) 51 (1), 2-11.

McDiarmid, M., Oliver, M., Ruser, J., Gucer, P., 2000. Male and female rate differences in carpal tunnel syndrome injuries: personal attributes or job tasks? Environ. Res. 83 (1), 23-32.

McDiarmid, M.A., Gucer, P.W., 2001. The "GRAS" status of women's work. J. Occup. Environ. Med. 43 (8), 665-669.

Meinert, C.L., Gilpin, A.K., 2001. Estimation of gender bias in clinical trials. Stat. Med. 20 (8), 1153-1164.

Mergler, D., 1995. Adjusting for gender differences in occupational health studies. In: Messing, K., Neis, B., Dumais, L. (Eds.), Invisible: Women's Occupational Health. Gynergy Books, Charlottetown, Prince Edward Island, pp. 236-251.

Messing, K., 1998. One-Eyed Science: Occupational Health and Women Workers. Temple University Press, Philadelphia.

Messing, K., 2002. La place des femmes dans les priorités de recherche en santé au travail au Québec. Ind. Relat./Relat. Ind. 57 (4), $660-686$.

Messing, K., Boutin, S., 1997. La reconnaissance des conditions difficiles dans les emplois des femmes et les instances gouvernementales en santé et en sécurité du travail. Relat. Ind./Ind. Relat. 52 (2), 333-362.

Messing, K., de Grosbois, S., 2001. Women workers confront one-eyed science: building alliances to improve women's occupational health. Women Health 33 (1/2), 125-143.

Messing, K., Stevenson, J., 1996. Women in procrustean beds: strength testing and the workplace. Gender Work Org. 3 (3), 156-167.

Messing, K., Punnett, L., Bond, M., Alexanderson, K., Pyle, J., Zahm, S., Wegman, D., Stock, S.R., de Grosbois, S., 2003. Be the fairest of them all: challenges and recommendations for the treatment of gender in occupational health research. Am. J. Ind. Med. 43, 618-629.

Niedhammer, I., Saurel-Cubizolles, M.-J., Piciotti, M., Bonenfant, S., 2000. How is sex considered in recent epidemiological publications on occupational risks? Occup. Environ. Med. 57, 521-527.

Nykvist, K., Kjellberg, A., Bildt, C., 2002. Causal explanations for common somatic symptoms among women and men. Int. J. Behav. Med. 9 (3), 286-300.

Ortiz-Hernandez, L., Tamez-Gonzalez, S., Martinez-Alcantara, S., Mendez-Ramirez, I., 2003. Computer use increases the risk of musculoskeletal disorders among newspaper office workers. Arch. Med. Res. 34 (4), 331-342.

Parker, S., 2000. Nutrition, weight and body image. In: Goldman, M., Hatch, M. (Eds.), Women and Health. Academic Press, New York, pp. $578-588$.

Punnett, L., Herbert, R., 2000. Work-related musculoskeletal disorders: is there a gender differential, and if so, what does it mean? In: Goldman, M., Hatch, M. (Eds.), Women and Health. Academic Press, New York, pp. 474-492.

Ramasubbu, K., Gurm, H., Litaker, D., 2001. Gender bias in clinical trials: do double standards still apply? J. Womens Health Gender Based Med. 10 (8), 757-764.

Reid, J., Ewan, C., Lowy, E., 1991. Pilgrimage of pain: the illness experiences of women with repetition strain injury and the search for credibility. Soc. Sci. Med. 32 (5), 601-612.

Sallsten, G., Barregard, L., 1997. Urinary excretion of mercury, copper and zinc in subjects exposed to mercury vapour. Biometals 10 (4), $357-361$.
Seppäla, P., 2001. Experience of stress, musculoskeletal discomfort, and eyestrain in computer-based office work: a study in municipal workplaces. Int. J. Human-Computer Interact. 13 (3), 279-304.

Setlow, V., Lawson, C.E., Woods, N.F. (Eds.), 1998. Gender Differences in Susceptibility to Environmental Factors. National Academy Press, Washington, DC.

Statistics Canada, 2001. Employment by detailed industry and sex. Statistics Canada, Catalogue no. 71D0004XCB, http://www.statcan.ca/english/Pgdb/labor10a.htm accessed November 26, 2002.

Stellman, J.M., 1978. Women's Work, Women's Health. Pantheon Books, New York.

Stellman, J.M., Daum, M.H., 1973. Work Is Dangerous to Your Health: A Handbook of Health Hazards in the Workplace and What You Can Do About Them. Pantheon Books, New York.

Stellman, J.M., Henifin, M.S., 1983. Office Work Can Be Dangerous to Your Health. Pantheon Books, New York.

Stetson, D.S., Albers, J.W., Silverstein, B.A., Wolfe, R.A., 1992. Effects of age, sex and anthropometric factors on nerve conduction measures. Muscle Nerve 15, 1095-1104.

Symanski, E., Sallsten, G., Barregard, L., 2000. Variability in airborne and biological measures of exposure to mercury in the chloralkali industry: implications for epidemiologic studies. Environ. Health Perspect. 108 (6), 569-573.

Thébaud-Mony, A., 2003. Justice for asbestos victims and the politics of compensation: the French experience. Int. J. Occup. Environ. Health 9 (3), 280-286.

Torgén, M., Kilbom, A., 2000. Physical work load between 1970 and 1993 - did it change? Scand. J. Work Environ. Health 26 (2), $161-168$.

Urban, P., Lukas, E., Nerudova, J., Cabelkova, Z., Cikrt, M., 1999. Neurological and electrophysiological examinations on three groups of workers with different levels of exposure to mercury vapors. Eur. J. Neurol. 6 (5), 571-577.

Wahlstrom, J., Lindegard, A., Ahlborg Jr., G., Ekman, A., Hagberg, M., 2003. Perceived muscular tension, emotional stress, psychological demands and physical load during VDU work. Int. Arch. Occup. Environ. Health, 76 (8), 584-590.

Wegman, D.H., 1992. The potential impact of epidemiology on the prevention of occupational disease. Am. J. Public. Health 82 (7), 944-954.

Williams, P., Frumkin, H., Pierce, M.L., Manning, C.C., Elon, L., Sanders, A.G., 2000. Renconstruction of occupational mercury exposures at a chloralkali plant. Occup. Environ. Med. 58, 81-86.

Wizemann, T.M., Pardue, M.L. (Eds.), 2001. Exploring the Biological Contributions to Human Health: Does Sex Matter? National Academy Press, Washington, DC.

Women's Health Bureau, Health Canada, 2000. Health Canada's Gender-Based Analysis Policy. Health Canada, Ottawa.

Yokoyama, K., Araki, S., Sato, H., Aono, H., 2000. Circadian rhythms of seven heavy metals in plasma, erythrocytes and urine in men: observation in metal workers. Ind. Health 38 (2), 205-212.

Zahm, S.H., Blair, A., 2003. Occupational cancer among women: where have we been and where are we going? Am. J. Ind. Med. 44 (6), 565-575.

Zahm, S.H., Pottern, L.M., Lewis, D.R., Ward, M.H., White, D.W., 1994. Inclusion of women and minorities in occupational cancer epidemiological research. J. Occup. Med. 36 (8), 842-847.

Zahm, S.H., Ward, M.H., Silverman, D.T., 2000. Occupational cancer. In: Goldman, M., Hatch, M. (Eds.), Women and Health. Academic Press, New York, pp. 493-502. 